\title{
AS DINÂMICAS DE FLUXOS DO COMÉRCIO ATACADISTA DE AUTOSSERVIÇO E SUAS IMPLICAÇÕES NA ESTRUTURAÇÃO DA PERIFERIA URBANA DE UBERLÂNDIA-MG
}

\author{
Leandro Oliveira Silva \\ Mestre em Arquitetura e Urbanismo - UFU \\ silva-lo@hotmail.com \\ Fernando Garrefa \\ Professor Associado da Faculdade de Arquitetura e Urbanismo da UFU \\ fgarrefa@ufu.br
}

\begin{abstract}
RESUMO
Mesclando características de atacado e varejo, os "atacarejos" são uma modalidade de comércio crescente no Brasil. Em Uberlândia - MG, cidade que desde sua gênese tem no setor atacadista uma de suas potências, esses estabelecimentos têm se instalado às margens da infraestrutura rodoviária que delimita sua periferia física. A partir dessa condição, esse estudo busca compreender as dinâmicas de fluxos a partir desses estabelecimentos e suas implicações no espaço urbano, em especial as zonas periféricas lindeiras aos eixos viários de Uberlândia. A pesquisa contou com extensa coleta de dados em campo e tratamento estatístico, além de estar amparada em pressupostos teóricos. Os resultados apontaram para significativas alterações na configuração e na dinâmica do espaço da cidade.
\end{abstract}

Palavras-chave: Atacadistas de autosserviço. Fluxo urbanos. Periferia urbana. Dinâmica urbana. Morfologia urbana.

\section{THE DYNAMICS OF FLOW FROM SELF-SERVICE WHOLESALE TRADE COMPANIES AND THE IMPLIES IN THE STRUCTURATION OF THE URBAN PERIPHERY IN THE CITY OF UBERLÂNDIA-BRAZIL.}

\begin{abstract}
Mixing characteristics of retail and wholesale trade, self-service wholesales are a rising typology in Brazil. In Uberlândia-MG, which has since its genesis the wholesale companies as one of its strengths, these undertakings have been installed alongside the roads infrastructure that limits its physical periphery. Considering this condition, this study aims to understand the dynamics of flow from these establishments and their implications for urban morphology, especially in the peripheral areas bordering the road axes of Uberlândia. The research counted on a wide data collection, field work, statistical processing and revision of theoretical literature. The results pointed out significant changes in the configuration and in the dynamic of the urban spaces.
\end{abstract}

Keywords: Self-service wholesalers. Urban flows. Urban periphery. Urban morphology.

\section{INTRODUÇÃO}

Esse trabalho tem por objetivo analisar a dinâmica de fluxos a partir dos estabelecimentos atacadistas de autosserviço e suas implicações na configuração do espaço urbano do município de Uberlândia-MG, em especial as áreas periféricas delimitadas pelos eixos rodoviários no interior e nas bordas da cidade, nos quais está concentrada a maior parte dos edifícios dessa categoria. A pesquisa que originou esse artigo operou em um recorte físico e temporal coincidente com as ações de suporte ao setor atacadista, consubstanciadas em obras de infraestrutura no sistema rodoviário dentro do perímetro urbano, entre os anos de 2005 e 2015 - relacionadas ao PAC (Programa de Aceleração do

$\begin{array}{lllll}\text { Caminhos de Geografia } \quad \text { Uberlândia-MG } & \text { v. 21, n. } 75 & \text { Jun/2020 } & \text { p. 264-283 Página } 264\end{array}$


Crescimento) e ao Crema (Contrato de Reabilitação e Manutenção de Rodovias). Dentre essas destacam-se obras urbanas, como construção de viadutos, trincheiras, recapeamento de vias (caso dos 5,1 km do trecho urbano da BR-050 que interliga os viadutos Regis Bittencourt e o da Avenida João Naves de Ávila), conforme reportagem do Correio de Uberlândia, de 15 de julho de 2014. Bem como, "melhoria do sistema rodoviário regional (duplicação da rodovia 365 , do $\mathrm{km} 622$ ao entroncamento com a BR 153 e da BR 050, entre Uberlândia e Araguari)" (SOARES et al, 2010, p. 203).

O município de Uberlândia, localizado na mesorregião do Triângulo Mineiro e Alto Paranaíba, no estado de Minas Gerais, apresenta atualmente uma configuração espacial que resulta, dentre outros fatores, da dinâmica do setor atacadista. Isso ocorre em função da especialização funcional desse no referido ramo da economia, uma vez que esta surge como entreposto comercial (SOARES, 1995) e sedia importantes empresas de distribuição e comércio atacadista. Como resultado, o município dispõe de infraestrutura voltada para a atuação dos atacadistas, destacando-se a infraestrutura viária, sendo que a mesma recebe fluxos de diversos pontos do território regional e nacional, por meio das rodovias federais e estuais que passam por ela (BR-050, BR-365, BR-452, BR-455, BR-497), além da Ferrovia Centro Atlântica (FCA).

A cidade já contava com a estação ferroviária da estrada de ferro da Mogiana, desde 1895, que, todavia, era pequena (SOARES, 1995). Entretanto, mesmo não sendo de grande significância nesse momento, contribuiu também para a estruturação econômica do munícipio. Tanto Soares (1995), como Moura \& Soares (2009) concordam que nesse período a cidade carecia de infraestrutura, fato que motivou a criação, em 1907, de um traçado urbanístico com o objetivo de conectar a malha urbana existente à Estação Mogiana, além de "criar uma cidade cuja imagem representasse a modernidade, melhorasse a sua estética e funcionalidade. Um dos resultados visíveis dessas motivações foi a transformação do seu sistema viário em um traçado ortogonal, mesclado de praças" (CLEPS, 2008, p. 28). Soares et al (2010, p. 165) ressaltam que "a entrada de Uberlândia nesse cenário de desenvolvimento rodoviário deu-se, efetivamente, com a criação da Companhia Mineira de Autoviação Intermunicipal, em 1912".

Além disso, outros fatores como "a construção da ponte Afonso Pena (1910) e de uma malha urbana de estradas de rodagem (1912)" ampliaram os fluxos de mercadoria e informações na região do Triângulo Mineiro, beneficiando principalmente os municípios de Uberaba, Araguari e Uberlândia (BESSA, 2007, p. 114). Esses investimentos na malha rodoviária no Triângulo Mineiro estabeleceram "47 linhas intermunicipais, totalizando $2.859 \mathrm{~km}$; e, em Goiás, via ponte Afonso Pena, foram 23 linhas intermunicipais, totalizando $2.043 \mathrm{~km}$ " (BESSA, 2007, p. 122). Tais investimentos visando à integração dos municípios que não dispunham de estações ferroviárias direcionaram, por meio das novas conexões rodoviárias, os fluxos para Uberlândia, que até 1905 dispunha de "11 armazéns de varejo e atacado, além de estabelecimentos comerciais de secos e molhados" (BESSA, 2007, p. 122).

Entre as décadas de 1940 e 1970 uma série de fatores também contribui para o desenvolvimento econômico e o crescimento da mancha urbana de Uberlândia, dentre eles: a atuação já destacada de Alexandrino Garcia e Alair Martins, a atuação política de Rondon Pacheco, a criação dos armazéns das atuais empresas de comércio e distribuição atacadista (Arcom, Irmãos Kehdi, Peixoto e União), na década de 1960. Além disso ainda pode-se mencionar a construção de Brasília e Goiânia na década de 1960, a criação Universidade Federal de Uberlândia e a implantação do Distrito Industrial na década de 1970 (SOARES, 1995).

Outro fato a ser destacado é a inauguração da nova estação ferroviária na década de 1970, que chama a atenção uma vez que a estação ferroviária até então instalada na área central da cidade (atual Praça Sérgio Pacheco), foi transferida para o bairro Custódio Pereira, que está localizado no Setor Leste da cidade, nas proximidades do aeroporto. A Universidade também teve seus dois primeiros campi instalados nesse setor da cidade, sendo um deles no bairro Umuarama, também nas proximidades da área que hoje comporta o aeroporto e, o outro no bairro Santa Mônica, mais próximo ao Setor Central.

Todo esse capital alocado na forma de infraestrutura contribuiu para que outras empresas do setor atacadista também se instalassem no município. Esse movimento contribuiu para a diversificação e ampliação do setor atacadista no município de Uberlândia, culminando em um processo de reestruturação do espaço da cidade, por meio da expansão e readequação da infraestrutura existente, a fim de dar suporte à atuação dos atacadistas. Assim, surge uma nova configuração e

\begin{tabular}{llllll}
\hline Caminhos de Geografia & Uberlândia-MG & v. 21, n. 75 & Jun/2020 & p. 264-283 Página 265
\end{tabular}


também uma nova dinâmica no espaço da cidade de Uberlândia, como poderá ser visto nesse trabalho.

A relação dos estabelecimentos da modalidade de atacado de autosserviço com a periferia urbana fez parte das estratégias locacionais das empresas do setor que assim estabeleceram um padrão de localização redefinindo por completo a dinâmica urbana em seus eixos e entorno. As estratégias locacionais de tais empreendimentos contemplam espaços delineados para um intenso fluxo de veículos, os quais realizam a conexão entre diferentes pontos da cidade e do território.

Embora a questão dos fluxos seja preponderante para a instalação desses equipamentos, nota-se que na maioria dos casos elas acabam demandando constantes obras de manutenção e reestruturação viária para comportar tais fluxos. O que se deve tanto ao aumento da frota, quanto à dinamização desses espaços por meio da instalação desses e de outros estabelecimentos em seu entorno.

Coronado (2007, p. 6) afirma que "A função do setor atacadista tem sido historicamente definidora do comércio, pois cabe ao atacadista fomentar a produção, importar mercadorias e distribuí-las aos mais longínquos lugares dentro e fora do país". Assim, evidencia-se a importância das atividades do setor para o abastecimento, tanto da população, como da indústria.

A circulação apresenta-se, desta forma, como um fator de suma importância para esse setor. Harvey (2005, p. 49) atribui dois aspectos à circulação, são eles:

(...) o movimento físico real de mercadorias do lugar de produção ao lugar de consumo, e o custo real ou implícito ligado ao tempo consumido e às mediações sociais (a cadeia de atacadistas, varejistas, operações bancárias etc.) necessárias para que a mercadoria produzida encontre o usuário final.

Outro ponto abordado por Harvey (2005) no que diz respeito à circulação, e que merece destaque, é que "no custo de circulação, a capacidade de economizar depende da natureza das relações de transporte estabelecidas, e, nesse caso, parece haver uma tendência dinâmica em favor da concentração" (HARVEY, 2005, p. 52).Sposito \& Sposito (2012) destacam que "as novas tecnologias aceleram a circulação do capital; as mudanças nos ritmos das empresas modificam seu papel em diferentes escalas e as formas de produção; e tudo isso se reflete nas transformações espaciais".

Diante disso, a intensificação de tais atividades, conta também com o desenvolvimento das telecomunicações e dos sistemas de transporte que têm possibilitado uma intensificação cada vez maior dos fluxos de informações e mercadorias, provocando constantes alterações no espaço (CASTELLS, 1992; GODOI, 2010; SANTOS, 2006).

Nota-se, dessa forma, o estabelecimento de redes que necessitam de um espaço que comporte as atividades demandadas para a realização do processo produtivo, sejam elas, materiais (transporte de mercadorias, por exemplo), ou, imateriais (fluxo de informação). Pois, "os lugares não desaparecem, mas sua lógica e seu significado são absorvidos na rede" (CASTELLS, 1992, p. 502) e, assim, "a infra-estrutura tecnológica que constrói a rede define o novo espaço [...]" (CASTELLS, 1992, p. 502). Ortigoza (2010, p. 18) também observou que,

[...] o espaço urbano, pela pressão da técnica global, vai se tornando fluido e passa, gradualmente, a atender à velocidade imposta pelas novas relações sociais de produção. Esses fluxos de informações e as funções urbanas, cada vez mais centradas no terciário, reproduzem o espaço continuamente".

Nesse contexto insere-se também a questão regional que envolve a rede urbana, por meio da qual se realiza o intercâmbio de mercadorias e informações (VILLAÇA, 2001). Considerando, desta maneira, as relações e os fluxos entre as cidades, também é possível estabelecer escalas de análise, capazes de apresentar de forma mais clara a abrangência, a

Caminhos de Geografia Uberlândia-MG $\quad$ v. 21, n. $75 \quad$ Jun/2020 $\quad$ p. 264-283 Página 266


densidade e a intensidade das relações que as cidades estabelecem umas com as outras nesse processo (SANTOS, 2006; SOUZA, 2003; SPOSITO, 2006).

Nota-se, também, que há uma maior diferenciação dos espaços, em função das especializações, e também da inserção desses lugares na lógica da produção capitalista. Uma vez que esses ficam sujeitos às estratégias de grupos com interesses pautados nesta lógica, os quais (que) envolvem a alocação de capital em determinados locais, a fim de obter vantagens e maior lucratividade, como observa Harvey (2005). Vargas (2001), ao discutir a relação entre comércio e cidade, enfatiza a importância da localização, considerando dentre outros fatores o transporte e os fluxos.

Desse modo, os processos espaciais na periferia urbana são influenciados por relações que se dão em escalas mais amplas. É nesse contexto que se insere o comércio e distribuição de mercadorias e, daí, surge também a necessidade de melhor compreendê-lo, assim como, compreender as consequências desse na organização do espaço das cidades. Vê-se, portanto, àquilo que Duarte (2006, p. 11) denominou de cidade-produto, "subordinada à lógica sistêmica da circulação de mercadorias". Esse modelo de cidade é caracterizado por constantes processos de reestruturação, com vistas a adaptar o espaço às demandas do capital (Harvey, 2005).

Assim, esse trabalho evidencia processos urbanos engendrados pela lógica do capital no espaço da cidade de Uberlândia-MG, mais especificamente, por meio das atividades relacionadas à circulação e distribuição de mercadorias. Processos que contribuem para a reestruturação desse espaço e para uma dinâmica de fluxos cada vez mais intensa, como poderão ser vistos a seguir.

\section{MATERIAIS E MÉTODOS}

Para identificar os fluxos e conectividade, 0 primeiro passo foi a realização da pesquisa de "fluxo volumétrico de veículos" e a aplicação do questionário de Origem-Destino na entrada de cinco dos estabelecimentos comerciais apresentados (Atacadão < Setor Norte>, Makro, Mart Minas <Setor Leste $>$, Mart Minas <Setor Oeste> e Bahamas Mix <Setor Central>) durante o período de uma semana a fim de obter as informações sobre a dinâmica espacial dos atacarejos, proporcionando o conhecimento da dinâmica dos fluxos gerados no âmbito desses estabelecimentos.

A amostragem, dessa forma, foi definida pelo método da "Linha de Contorno" utilizado nas pesquisas de Origem-Destino (Apêndice A). Assim, foi estabelecida uma quota amostragem não probabilística - de clientes para a pesquisa de $O D$ em cada um dos locais analisados - tendo sido aplicados 100 questionários junto aos clientes nas lojas do Mart Minas, Makro e Bahamas Mix e, 50 questionários na loja do Atacadão (devido à restrição de acesso nesta última), durante o período de uma semana -, a fim de se estabelecer uma comparação dos padrões observados in lócus. A partir disso, ressalta-se que a escolha pela amostragem não probabilística se deu em função das dificuldades de custo e operacionalização, além do fato das quotas, nesse caso, apresentarem resultados satisfatórios para o objetivo da pesquisa.

Esses dados após tabulados foram tratados em ambiente SIG - utilizando-se o software Quantum GIS - segundo a teoria dos campos vetoriais de interação, por meio das dissimilaridades direcionais, por exemplo, identificando as áreas de maior concentração dos fluxos de um determinado ponto (FERREIRA, 2014). Para tanto, utilizou-se a técnica de interpolação pelo algoritmo do inverso do quadrado das distâncias (IQD) - interpolação univariada por média ponderada. Parte-se de um ponto de interesse $x$, a partir do qual tomam-se as medidas $x_{i}$, onde $i$ varia de $1 \mathrm{a}$ n. O valor desconhecido é representado por $z(\mathbf{x})$ e o conhecido por $z_{i}$. Cada ponto recebe um peso $w_{i}$, avaliado com base em $d_{i}$ (distância de $\mathbf{x}_{i}$ para $\mathbf{x}$ (LONGLEY et al, 2013, p. 375). Então, a média ponderada é o resultado de:

$$
Z(\mathbf{x})=\sum_{i} w_{i} z_{i} / \sum_{i} w_{i}
$$

O peso nesse caso é atribuído pelo inverso do quadrado da distância, ou seja:

$$
w_{i}=1 / d_{i}^{2}
$$


Esse método de inferência espacial faz parte dos modelos determinísticos de estimação, os quais "têm por base critérios puramente geométricos em que as distâncias são euclidianas e não fornecem medidas de incerteza" (Yamamoto \& Landim, 2013, p. 22).

O resultado do processamento dos dados por meio do algoritmo IQD é um arquivo raster (.tif) cujos valores dos pixels representam o valor do atributo selecionado para o cálculo, que nesse caso é a frequência absoluta do fluxo de veículos/semana para cada um dos atacadistas, distribuídos pelos bairros de origem. Foram definidas então classes conforme a frequência absoluta para área de influência indo de "muito baixa" até "muito alta", dada a concentração do fluxo de veículos em cada bairro.

Também foram aplicadas técnicas de ponderação de matrizes a partir de modelos gravitacionais, com o objetivo de compreender a interação espacial de cada um dos pontos determinados com aqueles presentes na tabela de atributos (Ferreira, 2014). De acordo com Câmara et al [s. d.],

As redes são representadas através de matrizes de interação espacial, nas quais cada localidade onde se originam e destinam fluxos é representada por um ponto no espaço e os fluxos entre estas entidades são indicados como entradas numa matriz origem-destino.

Por meio dos dados de fluxo levantados na pesquisa de origem e destino (OD) foi possível estabelecer graus de interação (espacial) I entre os nós de uma determinada rede (FERREIRA, 2014, p. 180), para a construção do grafo (barras de fluxos) partindo de distintos pontos da cidade até cada um dos atacarejos.

Cabe destacar que os elementos que compõem o grafo, conforme destaca Ferreira $(2014$, p. 166), consistem em: conexão ou link - representado graficamente pelo objeto linha; Nó ou vértice - cujo objeto ponto o representa; região nodal - representada por um polígono; além da rede que integra esses objetos e dá forma ao arranjo espacial. Daí a sua aplicabilidade em ambiente de SIG, uma vez que esse trabalha com base numa estrutura de dados vetoriais georreferenciados (sistema geodésico), além da localização no âmbito da rede (sistema topológico) (FERREIRA, 2014, p. 167).

Em se tratando dos fluxos relacionados aos atacadistas de autosserviço, cabe salientar que a pesquisa centrou-se no fluxo de clientes que acessam as lojas, em veículos automotores, por meio do estacionamento que essas dispõem. Os fluxos relacionados ao abastecimento das lojas não foi contabilizado. A opção pelo fluxo de clientes está relacionada ao fato de que o principal objetivo da pesquisa é o de compreender a interação desses estabelecimentos com o espaço da cidade, bem como seus impactos.

As observações foram realizadas ao longo de uma semana nas lojas do Atacadão, Bahamas Mix (Setor Central), Makro e nas duas unidades do Mart Minas. No Makro e no Bahamas Mix foram realizadas duas observações em períodos distintos, o que possibilitou melhor conhecimento da dinâmica relacionada aos fluxos materiais gerados por tais estabelecimentos. Com base na coleta e espacialização dos dados foi possível observar a relação dos atacadistas de autosserviço com o espaço da cidade, como poderá ser visto a seguir.

\section{A REESTRUTURAÇÃO DA CIDADE DE UBERLÂNDIA: OS FLUXOS DO ATACAREJO E A CIDADE}

O Município de Uberlândia está localizado na Mesorregião do Triângulo Mineiro e Alto Paranaíba, na porção oeste do estado de Minas Gerais, como pode ser visto na figura 1. De acordo com a estimativa populacional do IBGE (2016) o município tem 666.672 habitantes, sendo o segundo mais populoso do estado. Uberlândia exerce o papel de polo regional, apresentando um PIB elevado (ver tabela 1) e grande diversidade de atividades econômicas. O Setor Atacadista é responsável por grande parte do capital que circula por Uberlândia, como mostram os dados da Fundação João Pinheiro (2013), uma vez que "Os serviços constituíram $66,8 \%$ do VAB de Uberlândia. O comércio, especialmente o segmento atacadista, teve grande participação na atividade local".

$\begin{array}{lllll}\text { Caminhos de Geografia } \quad \text { Uberlândia-MG } & \text { v. 21, n. } 75 & \text { Jun/2020 } & \text { p. 264-283 Página } 268\end{array}$


Figura 1 - Uberlândia-MG: Divisão do distrito urbano por setores (2014).

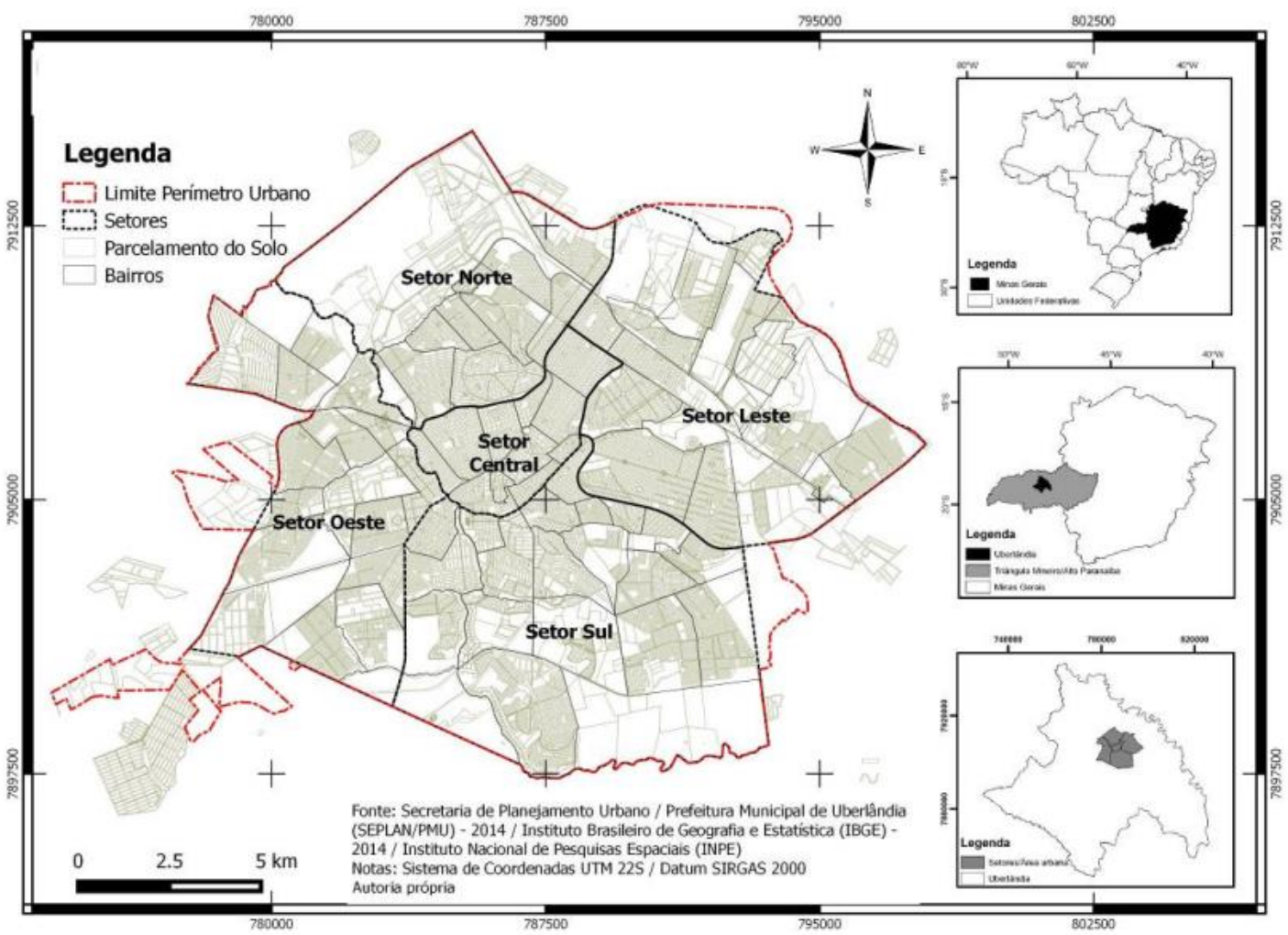

Fonte: dos autores (2019).

Tabela 1. Produto Interno Bruto - Por Unidade Territorial (2010 - 2013) ${ }^{1}$

\begin{tabular}{ccccc}
\hline UNIDADE TERRITORIAL / ANO & $\mathbf{2 0 1 0}$ & $\mathbf{2 0 1 1}$ & $\mathbf{2 0 1 2}$ & $\mathbf{2 0 1 3}$ \\
\hline Brasil & 3.885 .847 .000 & 4.373 .658 .000 & 4.805 .913 .000 & 5.316 .453 .957 \\
\hline Minas Gerais & 351.133 .915 & 400.049 .756 & 441.662 .103 & 441.662 .103 \\
\hline Triângulo Mineiro / Alto Paranaíba & 51.269 .912 & 57.810 .744 & 65.472 .550 & 71.693 .222 \\
\hline Uberlândia & 18.962 .924 & 19.567 .261 & 22.825 .878 & 25.774 .947 \\
\hline
\end{tabular}

Fonte: Instituto Brasileiro de Geografia e Estatística (IBGE) - 2016.

Nota: Variável = Produto Interno Bruto a preços correntes (Mil Reais).

No processo de ocupação do Triângulo Mineiro Bessa (2007, p. 90) recorda que "a condição de área de passagem ou espaço de circulação, criada no século XVIII, promoveu a fundação de algumas aldeias, isto é, o surgimento dos primeiros povoamentos aglomerados da região". Uberlândia surge em meio a esse contexto, enquanto entreposto comercial na Via do Anhanguera (Soares et al, 2010).

A atuação de políticos e empresários locais, desde o início do século $X X$, contribuiu para o direcionamento e alocação de capital em Uberlândia. Figuram entre esses Fernando Vilela da Silva, Alexandrino Garcia, Alair Martins, que funda em 1953 o armazém de secos e molhados Borges Martins, que viria a se tornar o Grupo Martins (atacadista distribuidor); e, também, Rondon Pacheco, que enquanto deputado e, principalmente, governador do estado de Minas Gerais (1971-1974), direcionou vários recursos e implantou infraestruturas em Uberlândia (Godoi, 2010). Diversas outras

$1 \quad$ Nesse período a participação (\%) de Uberlândia-MG no Valor Adicionado Bruto do Setor de Serviços de Minas Gerais foi de: 4,9\% em 2010, 4,8\% em 2011, 5,0\% em 2012 e 2013. (Fundação João Pinheiro, 2013).

$\begin{array}{llllll}\text { Caminhos de Geografia } & \text { Uberlândia-MG } & \text { v. } 21, \text { n. } 75 & \text { Jun/2020 } & \text { p. 264-283 Página } 269\end{array}$


empresas do setor atacadista, tais como: Arcom, Irmãos Kehdi, Peixoto e União², surgiram entre as décadas de 1950 e 1970, enquanto o Grupo Aliança e a Udifrios surgiram entre os 1990 e 2000.

Diante disso, sobretudo, desde o ano de 2010, observou-se o aumento do número de lojas de atacado de autosserviço, ou, atacarejo, assim como de outras modalidades, tais como os operadores logísticos. Uberlândia atualmente conta com três grandes operadores logísticos, quais sejam: o Entreposto da Zona Franca de Manaus, o Porto Seco do Cerrado, estação aduaneira multimodal, instalada junto à Ferrovia Centro Atlântica no Distrito Industrial de Uberlândia, além do PK Center, um business park, que conta com Centros de Distribuição de empresas como Natura, B2W e Pepsico. O Entreposto da Zona Franca de Manaus e o PK Center encontram-se justapostos ao perímetro urbano, embora para além desse.

De acordo com a Associação Brasileira de Atacadistas e Distribuidores de Produtos Industrializados (ABAD), atualmente, no Brasil, o setor de comércio e distribuição atacadista está dividido da seguinte forma: Atacado Generalista com Entrega; Atacado Generalista de Balcão; Atacado Generalista de Autosserviço (Cash \& Carry / Atacarejo); Distribuidor Especializado ou Exclusivo; além dos agentes comerciais, quais sejam: Comercial (Broker) e Operador Logístico. As características atribuídas a cada um deles pela ABAD encontram-se no Quadro 1 - no quadro encontram-se somente as modalidades levantadas no município.

Além das modalidades do setor atacadista apresentadas no quadro 1, observa-se que "Os grandes hipermercados, que acabaram tornando-se também atacadistas, são sem sombra de dúvida, um desafio do atacado tradicional, visto que provocam reestruturação e busca de eficiência na gestão logística e melhor serviço ao cliente varejista" (CORONADO, 2007, p. 9).

Com base na classificação do IBGE, por sua vez, a atividade comercial é dividida em atacado e varejo, sendo que o "comércio atacadista revende mercadorias novas ou usadas, sem transformação, a varejistas, a usuários industriais, agrícolas, comerciais, institucionais e profissionais, ou a outros atacadistas", podendo ainda atuar como representante comercial ou agente do comércio (IBGE, 2019). Sobre o comércio atacadista o órgão atribui a seguinte tipificação: aquele que compra a mercadoria e a revende, atacadista representante ou agente de comércio (IBGE, 2019). Já com relação ao comércio varejista, segundo o IBGE, esse "revende mercadorias novas e usadas, sem transformação, principalmente ao público em geral, para consumo ou uso pessoal ou doméstico" e complementa que "as unidades comerciais que revendem tanto para empresas como para o público em geral devem ser classificados como varejistas" (IBGE, 2019).

Observa-se que os cash \& carry e atacarejos realizam atividades de ambas as naturezas (atacado e varejo), assumindo, assim, uma característica bastante peculiar no que diz respeito à sua atuação no comércio, segundo a Classificação Nacional de Atividades Econômicas (CNAE), do IBGE, esta categoria definida pela ABAD como atacadista de autosserviço se enquadra no código 4639-7/02, definida como: Comércio atacadista de produtos alimentícios em geral, com atividade de fracionamento e acondicionamento associada (IBGE, 2019).

No caso de Uberlândia, com relação aos atacadistas de autosserviço (cash \& cary, ou, atacarejos), assistiu-se a um aumento expressivo do número de lojas na cidade do ano de 2010 em diante. Nesse ano foi instalada na cidade a loja do Atacadão no Setor Norte às margens da BR-365. No ano de 2013 instalam-se na cidade a as redes Mart Minas e Bahamas Mix, a primeira no Setor Leste, às margens da BR-050 e próxima ao Makro; a segunda, no Setor Central no armazém até então pertencente ao grupo local Aliança Atacadista e no qual funcionava a loja BIZ Super Atacado pertencente ao grupo, que em período coincidente migra para área próxima ao Atacadão.

2 A empresa União Atacado Distribuidor decretou falência em 15 de junho de 2016, conforme reportagem publicada pelo Correio de Uberlândia, em 16 de junho de 2016.

$\begin{array}{llllll}\text { Caminhos de Geografia } & \text { Uberlândia-MG } & \text { v. 21, n. } 75 & \text { Jun/2020 } & \text { p. 264-283 Página } 270\end{array}$


Quadro 1 - Comércio e Distribuição Atacadista em Uberlândia (2014).

\begin{tabular}{|c|c|c|c|}
\hline Modalidade & Característica & $\begin{array}{l}\text { Área } \\
\text { média } \\
\text { (ha) }\end{array}$ & Localização \\
\hline $\begin{array}{c}\text { Atacado Generalista } \\
\text { com entrega }\end{array}$ & $\begin{array}{l}\text { Compra e vende produtos de fornecedores da } \\
\text { indústria, sem vínculo de exclusividade ou de território, } \\
\text { entregando no estabelecimento do cliente varejista. }\end{array}$ & 12,7 & $\begin{array}{l}\text { Distrito Industrial e } \\
\text { proximidades. }\end{array}$ \\
\hline $\begin{array}{c}\text { Atacado Generalista } \\
\text { de Balcão }\end{array}$ & $\begin{array}{l}\text { O atacado de balcão é a modalidade mais antiga do } \\
\text { atacado, na qual o varejista vai até o depósito e das } \\
\text { suas compras com o auxílio de um atendente, que } \\
\text { recebe a lista de produtos, separa e entrega a } \\
\text { mercadoria, que é transportada em veículo do próprio } \\
\text { comprador. }\end{array}$ & 2,3 & $\begin{array}{l}\text { Setor Central da cidade } \\
\text { e no entorno de } \\
\text { rodovias. }\end{array}$ \\
\hline $\begin{array}{l}\text { Atacado Generalista } \\
\text { de autosserviço } \\
\text { (Cash \& Carry / } \\
\text { Atacarejo) }\end{array}$ & $\begin{array}{c}\text { Compra e vende produtos de fornecedores da } \\
\text { indústria, sem vínculo de exclusividade. Nessa } \\
\text { modalidade, o cliente vai até a loja, escolhe e separa } \\
\text { ele mesmo os produtos, paga na saída e transporta as } \\
\text { compras em veículo próprio. }\end{array}$ & 1,6 & $\begin{array}{l}\text { Na área urbana, } \\
\text { principalmente, nas } \\
\text { margens de rodovias e } \\
\text { vias arteriais. }\end{array}$ \\
\hline Operador Logístico & $\begin{array}{l}\text { Empresa que recebe sua remuneração pelas funções } \\
\text { de distribuição física dos produtos e também de } \\
\text { movimentação e armazenagem de cargas para a } \\
\text { indústria, que assim não precisa manter depósito na } \\
\text { própria região em que atua seu operador logístico. }\end{array}$ & 25,7 & $\begin{array}{l}\text { No entorno de rodovias } \\
\text { e ferrovias, nas bordas } \\
\text { da cidade. }\end{array}$ \\
\hline
\end{tabular}

Fonte: Associação Brasileira de Atacadistas e Distribuidores de Produtos Industrializados - ABAD (2014).

Em 2015, começa a funcionar a segunda loja da rede Mart Minas e, também, da rede Bahamas Mix no "Praça Uberlândia Outlef", respectivamente nos setores Oeste e Leste, a primeira às margens da BR-365 e a segunda próximo à BR-050 e às lojas do Makro e Mart Minas Leste. Tem-se também a UDIFRIOS, outra loja de origem local, que funciona como atacarejo atendendo o setor de food service. Cabe destacar que o grupo Pão de Açúcar, que dentre outras, detém as redes de hipermercados Extra e de atacado (de autosserviço) Assaí, está realizando o fechamento de lojas do Extra e substituindo-as por lojas do Assaí em todo o país, como é possível observar em Uberlândia, com o encerramento das atividades da unidade do Extra localizada na Av. Rondon Pacheco (Setor Central), em junho de 2017, foi inaugurada uma loja do Assaí.

Observa-se que o padrão locacional das empresas do setor, embora influenciadas pelo zoneamento urbano pautado em critérios econômicos na definição da alocação das atividades no espaço da cidade, diz respeito, também à dimensão da área de influência que tais estabelecimentos dispõem. Disto resulta uma nova dinâmica espacial, a qual define novos padrões de deslocamentos no interior da cidade e altera também a forma do espaço, por meio de novas estruturas demandadas infraestrutura viária, principalmente - para a realização das atividades peculiares ao atacado, bem como, pela atração de outros usos dado o aumento do número de usuários do espaço no entorno de tais estabelecimentos. Nota-se, desta forma, a intensificação dos fluxos materiais no interior da cidade engendrada pelos atacadistas, sobretudo, da modalidade de autosserviço.

Em campo observou-se que os atacadistas de autosserviço atraem um número expressivo de consumidores que acessam a loja por meio de veículos automotores, principalmente em veículos de passageiro individual, aumentando significativamente o trânsito nos locais onde estão instalados. Como consequência, foi possível observar algumas alterações viárias (mudança de sentido, implantação de travessias elevadas, sinalização etc.) no entorno de alguns dos estabelecimentos analisados.

$\mathrm{Na}$ cidade de Uberlândia a concentração dos atacarejos se deu num importante eixo rodoviário que cruza a cidade e a conecta a diferentes pontos do território nacional, por meio das rodovias federais que o compõem, quais sejam as BR-050 e BR-365, recebendo fluxos ainda da BR-452, além de sua ligação com o Anel Viário Ayrton Senna nos setores Sul e Norte da cidade e dos fluxos intra-urbanos

$\begin{array}{lllll}\text { Caminhos de Geografia } & \text { Uberlândia-MG } & \text { v. } 21, \text { n. } 75 & \text { Jun/2020 } & \text { p. 264-283 }\end{array}$ Página 271


(ver figura 2). Estas vias tem um forte papel estruturador no espaço da cidade de Uberlândia, pois além de estabelecerem conexão com os demais pontos do território nacional, conectam diferentes setores da cidade, o que as tornam bastante atraentes para os atacadistas de autosserviço.

Figura 2 - Uberlândia-MG: Atacarejos e eixos viários (2019).

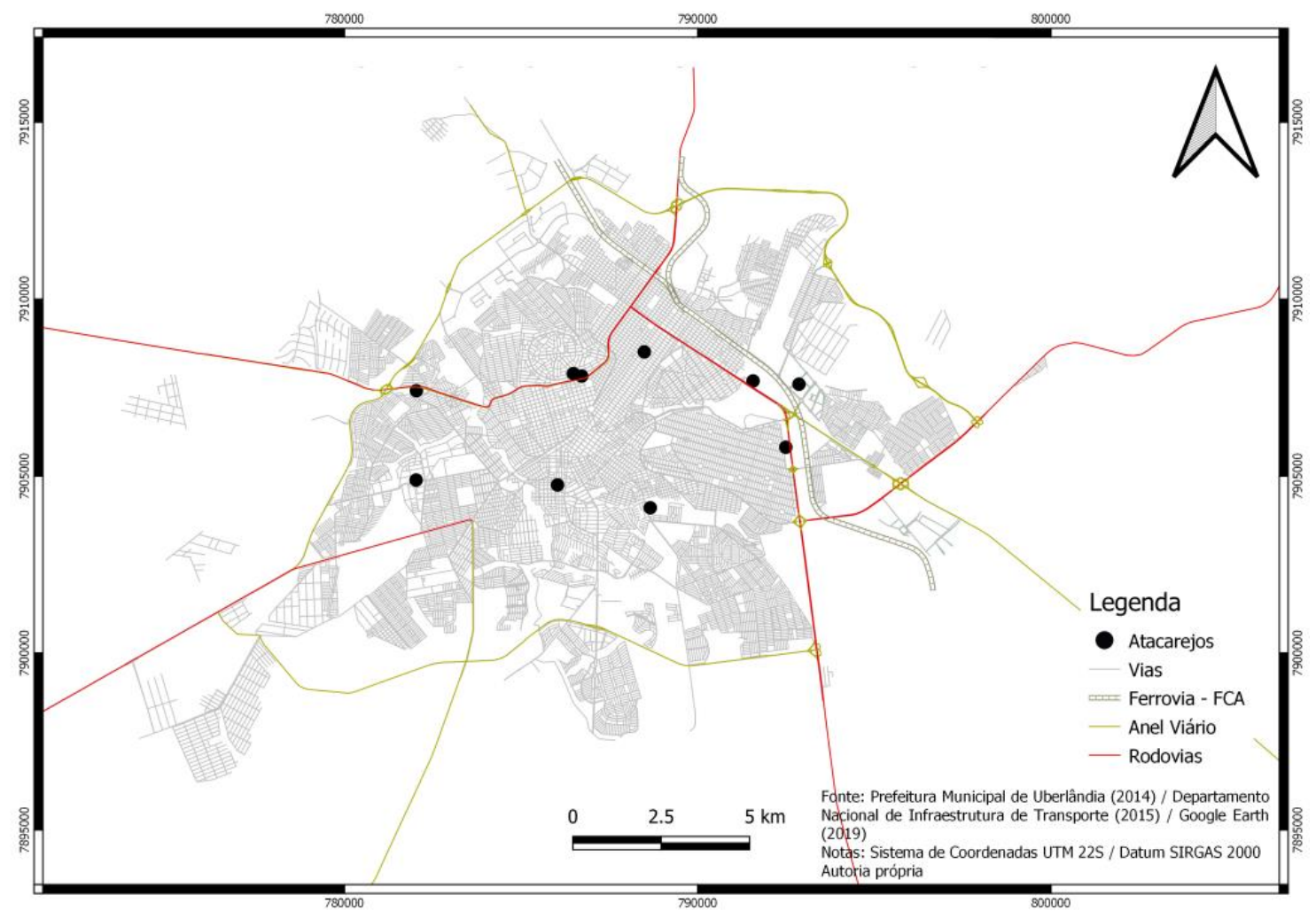

Fonte: dos autores (2019) Especialização funcional do eixo BR-050/BR-365 e a intensificação dos fluxos materiais.

Disso resulta a especialização funcional do eixo viário em destaque, que era fortalecida também pela presença da loja de hipermercado da rede Bretas Cerconsuld - fechada em junho de 2017, dada as estratégias de localização, marketing e ao mix de produtos, que tem estreita relação com as adotadas pelos atacadistas de autosserviço, guardadas as peculiaridades. Esse processo acarreta uma intensificação dos fluxos materiais, tanto de pessoas, como de mercadorias nesse espaço, o que altera a sua dinâmica e configuração.

Diante desse quadro, serão apresentadas algumas destas consequências que foram observadas em campo, quais sejam: os fluxos de veículos que acessam as lojas, os tipos predominantes de veículos e clientes, a interação com os demais pontos da cidade, por meio da contagem volumétrica de veículos e da pesquisa de Origem-Destino (OD) junto aos clientes que acessam estas lojas e as alterações na configuração do entorno imediato a esse espaço.

Observou-se que há dentre os clientes uma parte que se desloca de cidades do entorno para realizar compras, seja para abastecer sua casa, ou, comércio. Alguns desses inclusive se dirigem até as lojas em veículos de carga, como caminhões, realizando compras de maior volume e com frequência. A figura 3 apresenta os fluxos gerados pelos atacarejos com cidades da Mesorregião do Triângulo Mineiro e Alto Paranaíba e algumas que extrapolam esse limite, como João Pinheiro, Itumbiara e Corumbaíba, as duas últimas em Goiás. Isto evidencia o papel de polo regional que Uberlândia exerce. Todavia, deu-se maior ênfase aos fluxos contidos no perímetro urbano. No que diz respeito aos fluxos no interior da cidade observou-se que há um grande volume de veículos que se dirige com frequência a estas lojas. 
Figura 3 - Uberlândia-MG: Fluxo regional dos Atacadistas de Autosserviço (2016).

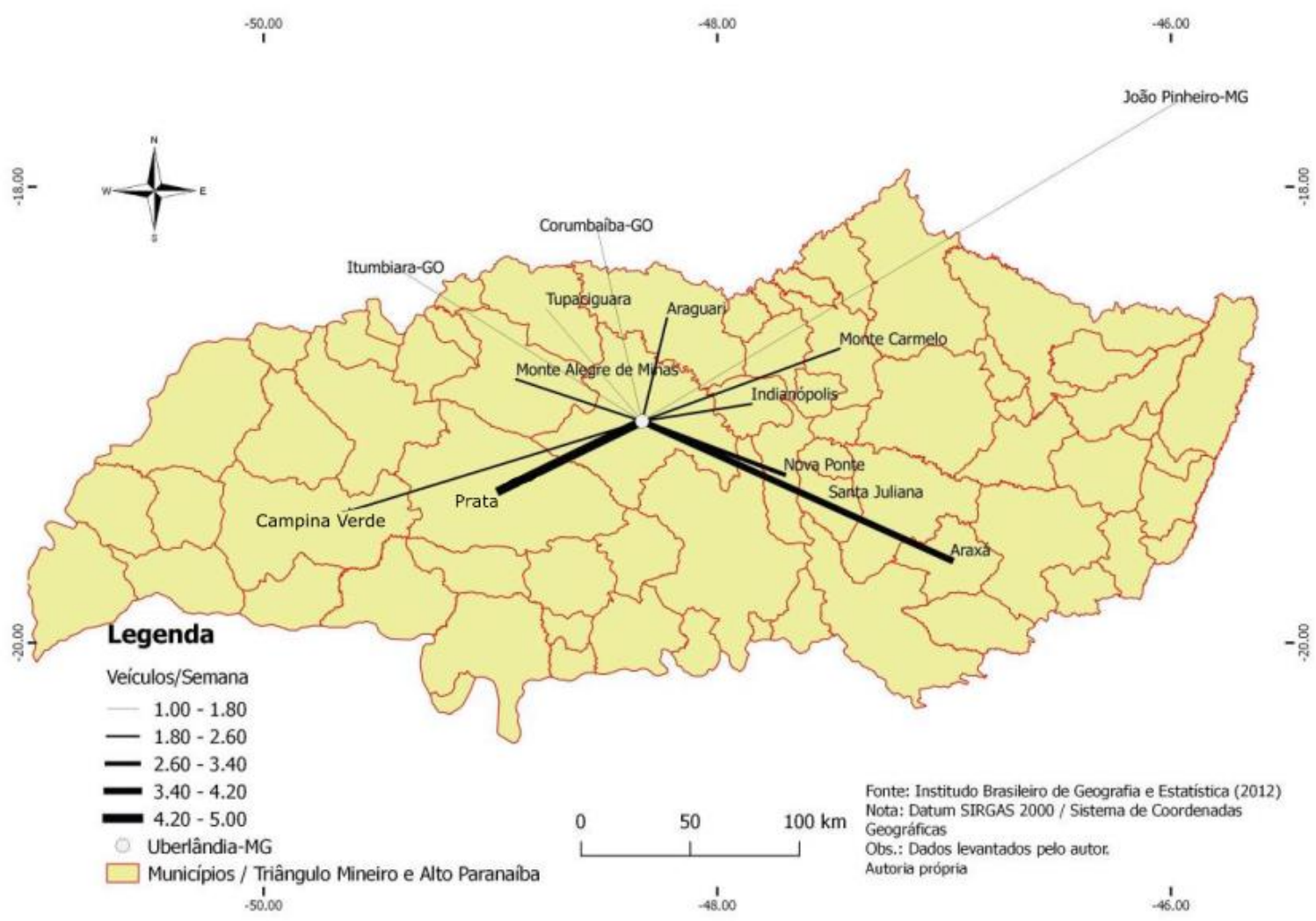

Fonte: dos autores (2019).

Somado o fluxo de veículos de passageiro de todas as lojas pesquisadas tem-se, semanalmente, aproximadamente 39.200 veículos se dirigindo para esses locais. Desses, em torno de 31.400 , concentrados nas lojas que estão instaladas ao longo das BR-050 e BR-365, uma vez que a loja do Bahamas Mix encontra-se no Setor Central, como já foi assinalado. Em média, cada estabelecimento atrai cerca de 7.850 veículos por semana

Dentre dos fluxos materiais gerados pelos atacadistas de autosserviço, destaca-se a predominância de veículos de passageiro, tais como carros, motocicletas, utilitários e camionetas. Esses representam $86,48 \%$ dos veículos que acessaram as lojas durante o período observado. Os veículos de carga leves, compreendidos pelos utilitários, caminhonete, camioneta, furgão, VUC (Veículo Urbano de Cargas) e motocicletas adaptadas correspondem a 13,09\%, já os veículos de carga pesados (caminhões e carretas) correspondem a $0,43 \%$, como pode ser visto na tabela 2 . Ao todo os veículos de carga somam mais de 6.100 veículos por semana.

Tabela 2 - Uberlândia-MG: Veículos que acessam aos atacarejos - por tipo em \% (2015/2016).

\begin{tabular}{ccccccc}
\hline $\begin{array}{c}\text { Tipo de Veículo / } \\
\text { Atacarejo }\end{array}$ & Atacadão & $\begin{array}{c}\text { Bahamas } \\
\text { Mix }\end{array}$ & Makro & $\begin{array}{c}\text { Mart Minas } \\
\text { Leste }\end{array}$ & $\begin{array}{c}\text { Mart Minas } \\
\text { Oeste }\end{array}$ & $\begin{array}{c}\sum \\
\text { Atacarejos }\end{array}$ \\
\hline Veículo de passageiro & $82,18 \%$ & $89,56 \%$ & $82,08 \%$ & $88,19 \%$ & $90,10 \%$ & $86,48 \%$ \\
\hline Veículo de carga leve & $17 \%$ & $10,44 \%$ & $17,28 \%$ & $11,35 \%$ & $9,77 \%$ & $13,09 \%$ \\
\hline $\begin{array}{c}\text { Veículo de carga } \\
\text { pesado }\end{array}$ & $0,82 \%$ & $0 \%$ & $0,62 \%$ & $0,45 \%$ & $0,13 \%$ & $0,43 \%$ \\
\hline
\end{tabular}

Notas: Dados coletados em campo por meio da Contagem Volumétrica de veículos durante o período de uma semana em cada um dos estabelecimentos analisados. Fonte: dos autores (2019).

$\begin{array}{llllll}\text { Caminhos de Geografia } \quad \text { Uberlândia-MG } & \text { v. } 21, \text { n. } 75 & \text { Jun/2020 } & \text { p. 264-283 Página } 273\end{array}$


Com relação à finalidade da visita às lojas a grande maioria se dá para a realização de compras, compreendendo $97,1 \%$, sendo que uma parcela desses também se dirige aos atacarejos a trabalho, que somados aos que vão somente para esta finalidade, corresponde a 5,1\%. Há ainda um grupo de $1,1 \%$ que vai às lojas para outras finalidades, dentre esses estão, por exemplo, prestadores de serviços (ver tabela 3).

Tabela 3 - Uberlândia-MG: Finalidade das visitas aos atacarejos - em \% (2015/2016).

\begin{tabular}{ccccccc}
\hline $\begin{array}{c}\text { Finalidade / } \\
\text { Atacarejo }\end{array}$ & Atacadão & $\begin{array}{c}\text { Bahamas } \\
\text { Mix }\end{array}$ & Makro & $\begin{array}{c}\text { Mart Minas } \\
\text { Leste }\end{array}$ & $\begin{array}{c}\text { Mart Minas } \\
\text { Oeste }\end{array}$ & $\begin{array}{c}\sum \\
\text { Atacarejos }\end{array}$ \\
\hline Compras & $92,16 \%$ & $97 \%$ & $99 \%$ & $98,99 \%$ & $100,00 \%$ & $97,10 \%$ \\
\hline Trabalho & $5,88 \%$ & $3 \%$ & $3 \%$ & $7,07 \%$ & $7,00 \%$ & $5,10 \%$ \\
\hline Outros fins & $3,92 \%$ & $0 \%$ & $1 \%$ & $1,01 \%$ & $1,00 \%$ & $1,10 \%$ \\
\hline
\end{tabular}

Notas: Dados coletados em campo por meio da Pesquisa de OD durante o período de uma semana em cada um dos estabelecimentos analisados.

Fonte: dos autores (2019)

Outro dado importante diz respeito ao destino da mercadoria, ou seja, se esta foi adquirida por cliente comercial (pequeno e médio varejo, grande varejo e atacado), ou, por cliente final (para uso doméstico). Viu-se que $76,1 \%$ dos clientes que acessam as lojas de atacarejo são clientes finais. Dentre os clientes comerciais a maior parcela é de pequenos e médios varejistas, que correspondem a $24,8 \%$, os grandes varejistas correspondem a $1,4 \%$ e os atacadistas $0,9 \%^{3}$, o que é possível verificar na tabela 4.

Tabela 4. Uberlândia-MG: Destino da mercadoria dos atacarejos- em \% (2015/2016).

\begin{tabular}{ccccccc}
\hline $\begin{array}{c}\text { Destino da mercadoria / } \\
\text { Atacarejo }\end{array}$ & Atacadão & $\begin{array}{c}\text { Bahamas } \\
\text { Mix }\end{array}$ & Makro & $\begin{array}{c}\text { Mart Minas } \\
\text { Leste }\end{array}$ & $\begin{array}{c}\text { Mart Minas } \\
\text { Oeste }\end{array}$ & $\begin{array}{c}\sum \\
\text { Atacarejos }\end{array}$ \\
\hline Pequeno / Médio Varejo & $35,56 \%$ & $20,83 \%$ & $35,05 \%$ & $18,56 \%$ & $19,18 \%$ & $24,80 \%$ \\
\hline Grande Varejo & $4,44 \%$ & $2 \%$ & $4,12 \%$ & $0 \%$ & $0 \%$ & $1,40 \%$ \\
\hline Atacado & $2,22 \%$ & $2 \%$ & $1 \%$ & $1,03 \%$ & $0 \%$ & $0,90 \%$ \\
\hline Doméstico & $60 \%$ & $81,25 \%$ & $68,04 \%$ & $82,47 \%$ & $81,82 \%$ & $76,10 \%$ \\
\hline
\end{tabular}

Notas: Dados coletados em campo por meio da Pesquisa de OD durante o período de uma semana em cada um dos estabelecimentos analisados.

Fonte: dos autores (2019).

Ressalta-se também a frequência das visitas às lojas que foi quantificada nas seguintes categorias: clientes que acessam as lojas mais de uma vez por semana, uma vez por semana, a cada 15 dias, uma vez ao mês e esporadicamente. O primeiro grupo corresponde a $29,5 \%$, esse é composto em sua maioria por pequenos e médios varejistas (panificadoras, restaurantes, lanchonetes, pizzarias e mercearias), com composição semelhante o grupo que acessa as lojas uma vez por semana compreende $21,7 \%$. Já o grupo o que acessa as lojas a cada quinze dias corresponde a $18 \%$, enquanto que os que vão mensalmente somam $19,1 \%$ e outros $11,8 \%$ se dirigem esporadicamente aos atacarejos. Esses três últimos grupos são compostos principalmente por clientes finais, tendo, todavia, participação de clientes comerciais também. Na tabela 5 é possível visualizar a distribuição pela frequência das visitas.

3 Dos clientes comerciais uma parcela disse também realizar compras para fins domésticos, o que explica a somatória dos percentuais, que ultrapassa os $100 \%$.

$\begin{array}{llllll}\text { Caminhos de Geografia } & \text { Uberlândia-MG } & \text { v. 21, n. } 75 & \text { Jun/2020 } & \text { p. 264-283 } & \text { Página } 274\end{array}$


Tabela 5 - Uberlândia-MG: Distribuição da frequência de visitas aos atacarejos- em \%(2015/2016).

\begin{tabular}{ccccccc}
\hline $\begin{array}{c}\text { Frequência / } \\
\text { Atacarejo }\end{array}$ & Atacadão & $\begin{array}{c}\text { Bahamas } \\
\text { Mix }\end{array}$ & Makro & $\begin{array}{c}\text { Mart Minas } \\
\text { Leste }\end{array}$ & $\begin{array}{c}\text { Mart Minas } \\
\text { Oeste }\end{array}$ & $\begin{array}{c}\sum \\
\text { Atacarejos }\end{array}$ \\
\hline $\begin{array}{c}\text { Mais de uma vez / } \\
\text { semana }\end{array}$ & $47,03 \%$ & $34 \%$ & $32 \%$ & $24,49 \%$ & $16,16 \%$ & $29,50 \%$ \\
\hline Uma vez / semana & $11,76 \%$ & $22 \%$ & $26 \%$ & $25,51 \%$ & $22,22 \%$ & $21,70 \%$ \\
\hline A cada 15 dias & $13,73 \%$ & $18 \%$ & $13 \%$ & $23,47 \%$ & $20,20 \%$ & $18 \%$ \\
\hline Uma vez ao mês & $13,73 \%$ & $14 \%$ & $18 \%$ & $20,41 \%$ & $25,25 \%$ & $19,10 \%$ \\
\hline Esporadicamente & $13,73 \%$ & $12 \%$ & $11 \%$ & $6,12 \%$ & $16,16 \%$ & $11,80 \%$ \\
\hline
\end{tabular}

Notas: Dados coletados em campo por meio da Pesquisa de OD durante o período de uma semana em cada um dos estabelecimentos analisados.

Fonte: dos autores (2019).

$\mathrm{Na}$ loja do Atacadão observou-se que há maior dispersão espacial dos fluxos analisados a partir da contagem volumétrica de veículos e da pesquisa de OD (ver figuras 4 e 5). Entende-se que essa maior capilaridade dos fluxos está relacionada, dentre outros fatores, à sua centralidade no tecido urbano de Uberlândia, uma vez que as demais lojas apresentam uma maior influência nos bairros mais próximos e de mais fácil acesso a elas, como poderá ser visto mais adiante.

Figuras 4 e 5 - Uberlândia-MG: Área de influência do Atacadão (2016).
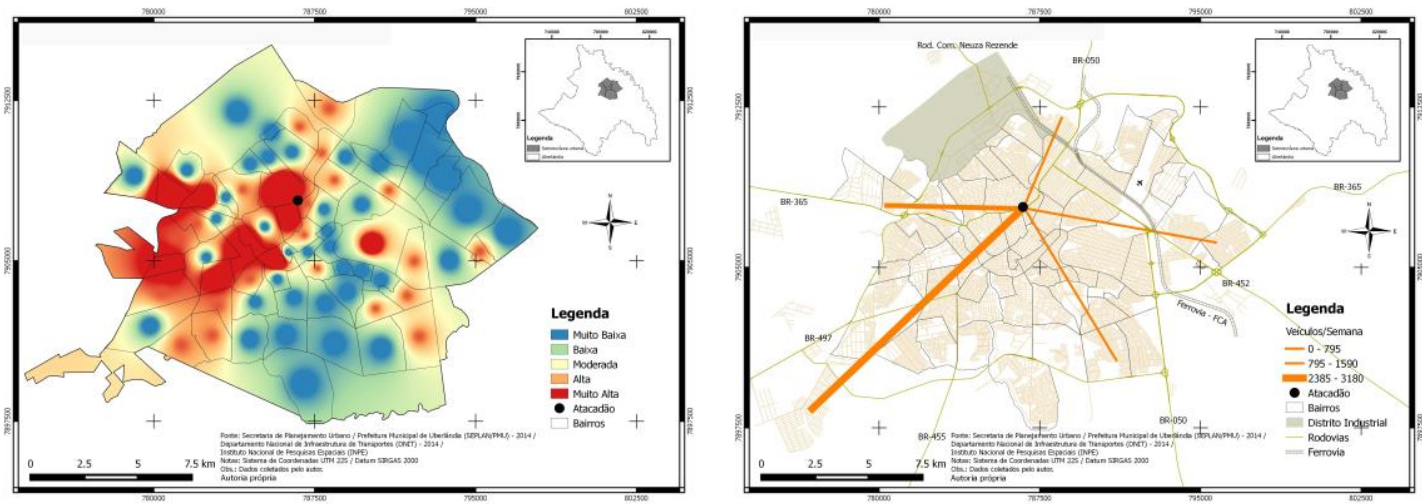

Fonte: dos autores (2019).

Além disso, notou-se que dentre os clientes que acessaram a loja, $82,18 \%$ o fizeram por meio de veículos de passageiro, enquanto que $17 \%$ acessaram a loja em veículos de carga leve, além de outros $0,82 \%$ que adentram a área do estacionamento em veículos de carga pesados (ver tabela 2). Esta característica, por sua vez, está ligada ao número de clientes domésticos como pôde ser observado. Se comparado aos outros atacarejos, com exceção do Makro, o percentual de clientes comerciais de pequeno e médio varejo é maior. Isto tem relação também com o número de veículos de carga apresentados acima, ainda que parte significativa dos comerciantes também se dirija à loja utilizando veículos de transporte de passageiro.

Com relação ao destino da mercadoria como já mencionado há predominância de clientes finais (destino doméstico), sendo que esses somam $60 \%$ dos clientes que acessam a loja. Todavia, há um percentual expressivo de clientes comerciais de pequeno e médio varejo, 35,56\%, como pode ser visto na tabela 4 . Já $4,44 \%$ são de clientes de grande varejo e outros $2,22 \%$ são clientes atacadistas. Uma parcela dos clientes comerciais disse também realizar compras para fins domésticos.

O Bahamas Mix está localizado no Bairro Brasil, no Setor Central da cidade, já próximo à divisa com o Setor Leste que é definida nesse bairro pelas rodovias BR-050 e BR-365. A loja instalada no antigo 
armazém do grupo Aliança Atacadista ocupa a área de um quarteirão; somados o estacionamento, estoque e administrativo.

Esta localização aliada ao traçado ortogonal do bairro Brasil torna a loja bastante acessível de qualquer ponto da cidade, muito embora a distância a determinados locais e o trânsito gerado pelas Avenidas Afonso Pena e João Pinheiro dificultem em parte esse acesso. Esses fatores, além da presença de outros estabelecimentos da modalidade em outros pontos da cidade contribuem para que a área de maior influência da loja seja mais concentrada se comparada à do Atacadão, como pode ser visto nas figuras 6 e 7 .

Figuras 6 e 7 - Uberlândia-MG: Área de influência do Bahamas Mix (2015/2016).
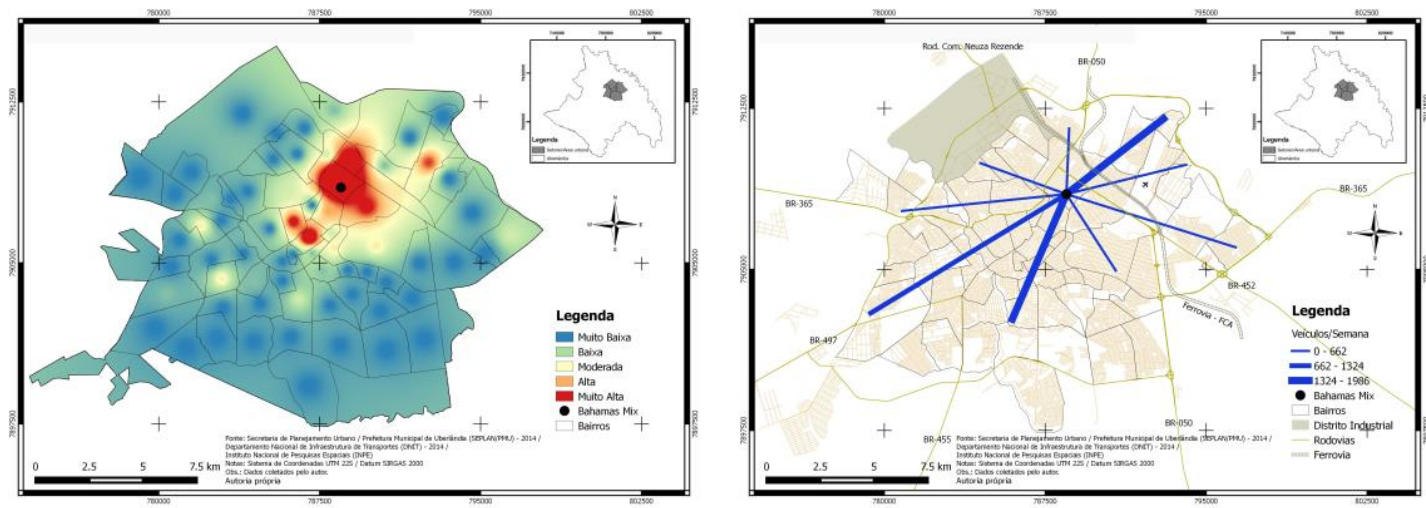

Fonte: dos autores (2017).

As pesquisas de contagem volumétrica de veículos e OD possibilitaram compreender os fluxos gerados pela loja. Dentre os veículos que acessaram a loja no período analisado $89,56 \%$ são de passageiro, enquanto que $10,44 \%$ são de carga leve e não foram contabilizados veículos de carga pesados na área do estacionamento. Esses números demonstram a característica da loja que atende um percentual maior de clientes finais se comparada ao Atacadão e ao Makro.

Com base no destino da mercadoria observa-se esta predominância de clientes finais, uma vez que $81,25 \%$ dos clientes que se dirigem à loja realizam compras para uso doméstico. Uma pequena parcela desses são também clientes comerciais, dos quais $20,83 \%$ são pequenos e médios varejistas, $2 \%$ são grandes varejistas e atacadistas, como pode ser visto na tabela 3 .

Esta composição da clientela tem relação com a localização do bairro e também com a característica desse, que apesar de dispor de áreas comerciais importantes no âmbito da cidade ao longo das avenidas principais é predominantemente residencial e bastante adensado, dado também à sua construção que data da década de 1930 (Moura \& Soares, 2009).

Com relação à frequência com que os clientes visitam a loja observou-se que $34 \%$ vão mais de uma vez por semana e, $22 \%$ ao menos uma vez por semana (ver tabela 4). Esse número está relacionado como já foi destacado em sua maior parte aos pequenos e médios varejistas. Todavia, no caso do Bahamas Mix parte dos clientes comerciais disse se dirigir à loja com relativa frequência. $O$ grupo de clientes que vai à loja a cada quinze dias soma $18 \%$, enquanto que $14 \%$ vão uma vez ao mês e outros $12 \%$ esporadicamente. Esses três últimos são compostos basicamente pelos clientes finais.

O Makro, por sua vez, não se insere na malha urbana da mesma forma que os demais atacarejos, uma vez que se encontra em uma área isolada pela barreira formada pela rodovia de um lado e por uma extensa área vazia de outro, tendo somente uma concessionária de veículos na mesma área. Todavia, o trecho da BR-050 no qual o Makro está instalado é um dos eixos viários com maior acessibilidade no sistema viário de Uberlândia. Além disso, o estabelecimento possui uma via que o conecta direto ao bairro Tibery, passando por uma trincheira que cruza a rodovia; a via marginal da rodovia o conecta com o bairro Custódio Pereira, a Alameda João Leão, que também possibilita o acesso tanto dos moradores da parte alta do Setor Leste, como daqueles que vão pela Avenida Anselmo Alves dos Santos no sentido oeste-leste, pois necessitam passar por ela após a rotatória em frente ao Praça Shopping Outlet.

$\begin{array}{llllll}\text { Caminhos de Geografia } & \text { Uberlândia-MG } & \text { v. 21, n. } 75 & \text { Jun/2020 } & \text { p. 264-283 Página } 276\end{array}$


Semelhante ao Atacadão o Makro apresenta um número mais expressivo de clientes acessando a loja em veículos de carga leve, os quais correspondem a $17,28 \%$ do total, os que acessam a loja por meio de veículo de carga somam $0,62 \%$. E a tendência da maior parte dirigindo veículos de passageiro, num total de $82 \%$ também foi notada (ver tabela 3 ). O que evidencia a tendência pela atração de clientes em veículos de passageiro, que em sua maioria são clientes finais.

Em se tratando do destino da mercadoria, dado por meio do qual se conhece o tipo de cliente, no caso do Makro, 35,05\% das mercadorias segue para o pequeno e médio varejo. Esse dado ratifica o argumento exposto no parágrafo anterior. Já para o grande varejo destina-se $4,12 \%$ das mercadorias que saem da loja, enquanto em torno de $1 \%$ segue para o atacado. Os clientes finais, somados aos clientes comerciais que também realizam compras para uso doméstico somam 68,04\%. A tabela 4 apresenta esta distribuição.

Desta composição da clientela, dentre outros fatores, tem-se como resultado uma área de influência expressiva no espaço da cidade, ainda que a maior influência esteja concentrada nas imediações da loja (ver figuras 8 e 9). Esta compreende os bairros Tibery, Santa Mônica e Custódio Pereira, além de uma mancha que se espalha pelo Setor Leste com uma alta concentração no bairro Morumbi. Exerce menor influência nos setores Central, Oeste e Sul.

Figuras 8 e 9 - Uberlândia-MG: Área de influência do Makro (2016).
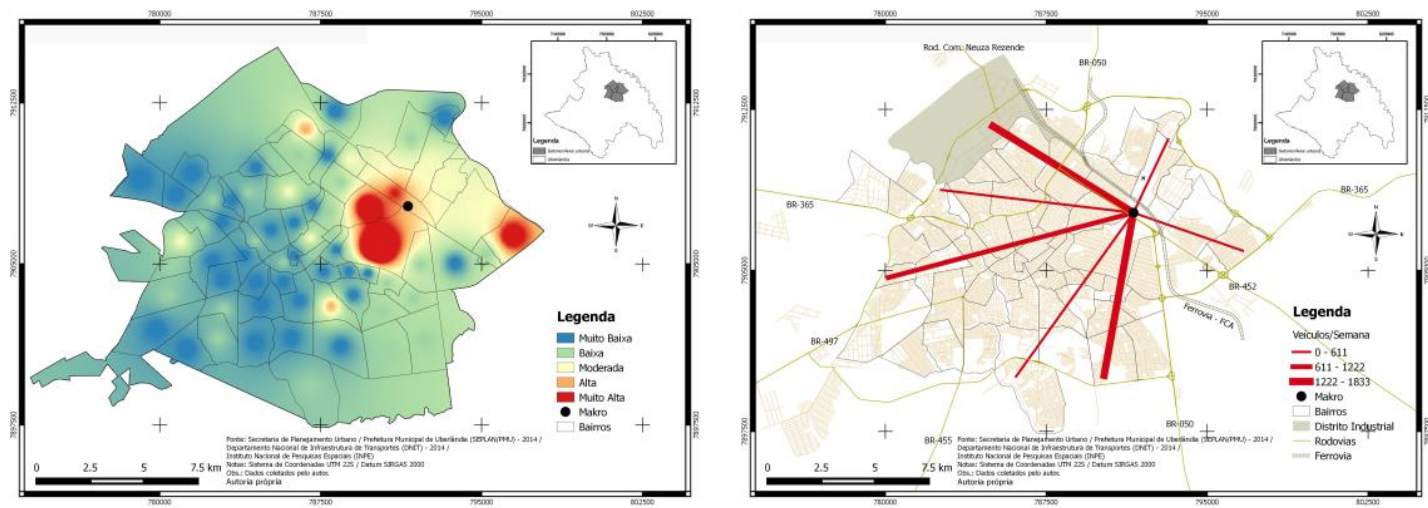

Fonte: dos autores (2017).

Já o Mart Minas localizado no Setor Leste está à margem da BR-050, no bairro Segismundo Pereira. A loja tem seu acesso principal voltado para o bairro pela rua Cleone Cairo Gomes. Todavia, há um acesso pela rodovia em um trecho sem pavimentação que liga a pista ao estabelecimento. $O$ acesso pelo bairro fica a poucos metros da Avenida Segismundo Pereira, que entronca com a BR-050 e canaliza o fluxo do setor até a Avenida João Naves de Ávila, nas proximidades do Campus Santa Mônica, da Universidade Federal de Uberlândia.

A área onde a loja está instalada é caracterizada por usos como oficinas de veículos e madeireiras, na face voltada para a rodovia. Já a face voltada para o bairro é predominantemente residencial, havendo somente comércios locais (bares, padarias, lanchonetes e farmácias). Isto somado ao fato de o estabelecimento estar próximo ao bairro Santa Mônica (o mais populoso da cidade ${ }^{4}$ ) corrobora para o fato de $82,47 \%$ das mercadorias consumidas na loja terem destino doméstico, representando uma maioria de clientes finais (ver tabela 4). Os pequenos e médios varejistas representam 18,56\% dos clientes e os atacadistas $1,03 \%$, dos quais uma parte também realiza compras para uso doméstico.

Esta característica da clientela faz com que haja maior concentração dos fluxos nos bairros mais próximos ao estabelecimento (ver figuras 10 e 11). Percebe-se que a loja tem influência por todo o Setor Leste, ainda que esta vá diminuindo à medida que se afasta da mesma. Exerce uma influência considerável também no Setor Sul, que é mais alta no bairro São Jorge e entorno, o que não se vê com os demais setores da cidade. População do bairro Santa Mônica: 35.737 habitantes (IBGE, 2010).

$\begin{array}{llllll}\text { Caminhos de Geografia } & \text { Uberlândia-MG } & \text { v. 21, n. } 75 & \text { Jun/2020 } & \text { p. 264-283 Página } 277\end{array}$


Figuras 10 e 11 - Uberlândia-MG: Área de influência do Mart Minas Leste (2016).
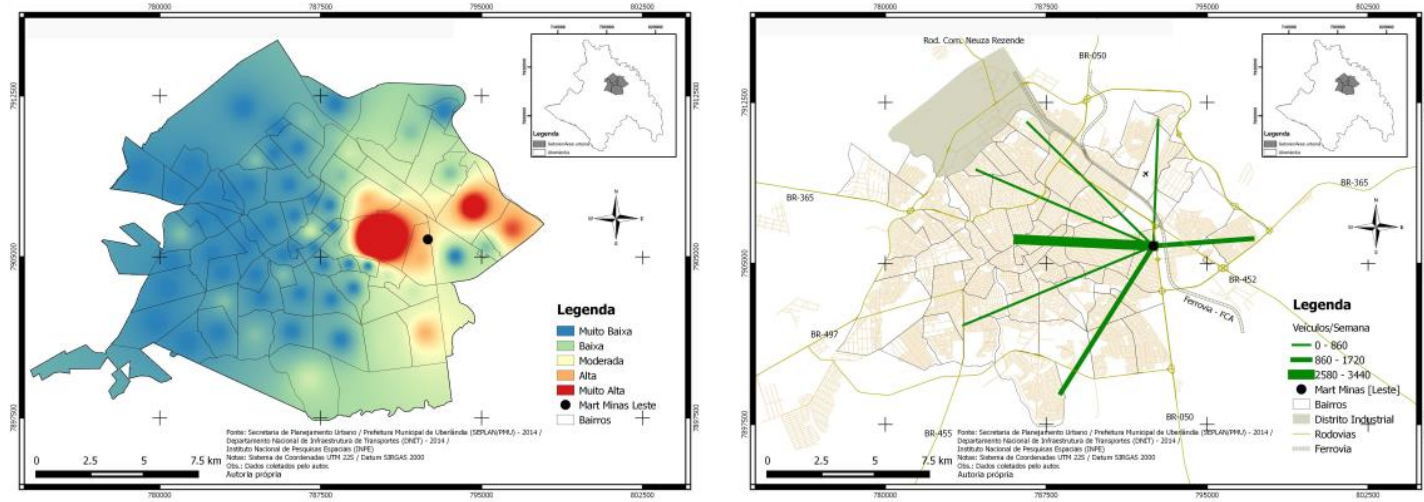

Fonte: dos autores (2017).

Com relação ao tipo de veículo observou-se que a maior parte dos clientes acessa a loja em veículos de passageiro, correspondendo a $88,19 \%$. Isto está relacionado à já destacada maioria de clientes finais e ao fato de que uma parte dos clientes comerciais acessam a loja também por meio desse tipo de veículo. Os veículos de carga leve correspondem a 11,35\%, enquanto os de carga pesado somam 0,45\% dos veículos que acessam o Mart Minas (Leste), como pode ser visto na tabela 3 .

O Mart Minas do Setor Oeste fica também à margem da rodovia, a BR-365 no caso, na saída para Monte Alegre de Minas. Todavia, esse até agosto de 2016, não dispunha de uma entrada diretamente pela rodovia como a outra loja da rede apresentada acima. A entrada/saída até então era realizada somente na face da loja voltada para o bairro Jardim Patrícia, no qual se encontra.

A área adjacente é composta por uma gleba vazia e algumas oficinas no entorno. O bairro, por sua vez, apesar de ter um comércio forte com a presença de supermercados e hipermercados, no entorno da loja é predominantemente residencial. O estabelecimento se beneficia desta dinâmica, além da travessia para outros bairros, pela Avenida dos Eucaliptos (a poucos metros da loja), que dá acesso à BR-365. Outra importante via de acesso é a Avenida Aspirante Mega que conecta a loja às avenidas Brigadeiro Sampaio e Getúlio Vargas, importantes vias de ligação entre os setores Oeste e Central.

Os dados da contagem volumétrica de veículos realizada no local demonstram que $90,10 \%$ dos clientes que acessam a loja por meio de veículos automotores, vão em veículos de passageiro. Os veículos de carga leve correspondem a 9,77\%, sendo que o número de veículos de carga pesado é praticamente nulo (ver tabela 3 ).

Assim como nos outros casos a predominância de veículos de passageiro indica o maior número de clientes finais. No caso do Mart Minas (Oeste) esse número é bastante superior ao das outras lojas, sendo que $81,82 \%$ das mercadorias destinam-se para o uso doméstico e $19,18 \%$ para pequeno e médio varejo, como é possível ver na tabela 4 . Nota-se que não há a presença de grandes varejistas e atacadistas realizando compras na loja, mas que apesar do número alto clientes finais, há uma porcentagem significativa de pequenos e médios varejistas. A área de influência do Mart Minas Oeste pode ser observada nas figuras 12 e 13. 
Figuras 12 e 13 - Uberlândia-MG: Área de influência do Mart Minas Oeste (2016).
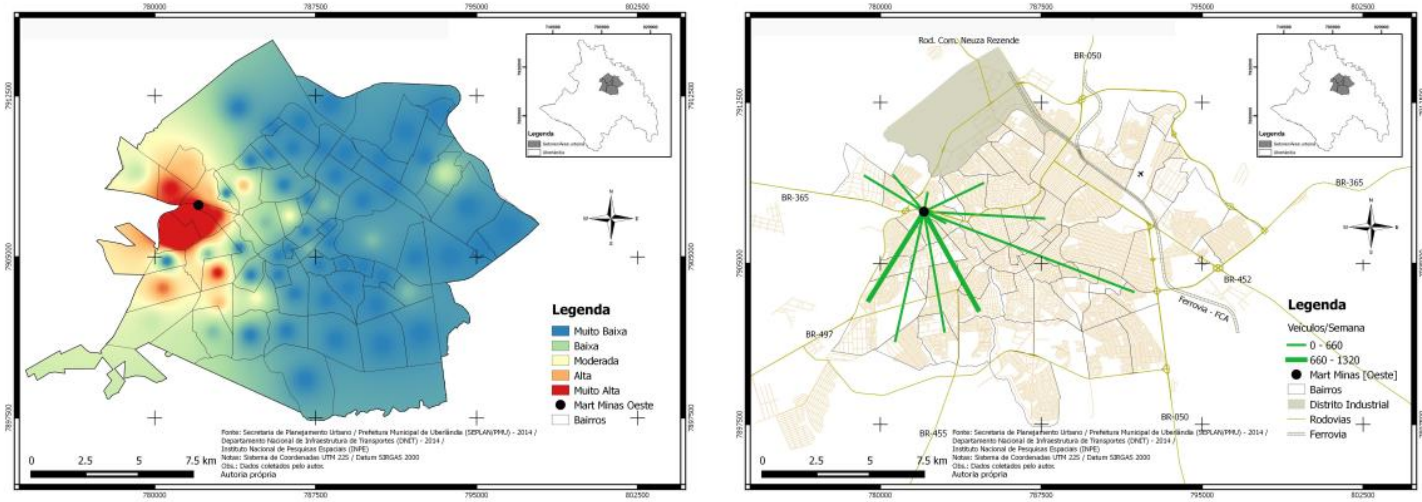

Fonte: dos autores (2017).

Com base nos dados observados, levando-se em conta o volume e diversidade de veículos, a dispersão dos fluxos pelo tecido urbano, devido ao potencial de atração de fluxos materiais que esses estabelecimentos têm, observa-se uma reconfiguração do espaço da cidade de Uberlândia em diferentes escalas. Primeiramente na escala da cidade, por meio das obras de infraestrutura viária já destacadas; depois na escala do bairro, tanto pela própria intensificação dos fluxos, como pelas mudanças da morfologia urbana, por meio das obras de infraestruturas instaladas e do adensamento do ambiente construído; e, por último, na pequena escala, alterando a relação dos usuários do espaço em função de tais processos espaciais.

Desse modo, observa-se que a configuração do espaço urbano está intrinsecamente ligada a questões que extrapolam esse espaço, principalmente, de cunho econômico, uma vez que há agentes atuando na produção do espaço das cidades a partir de lógicas e processos de ordem regional, nacional e, por vezes, global. Observa-se, também, que esse padrão locacional dos estabelecimentos de atacarejo, está relacionado à obtenção de vantagens no âmbito do espaço da cidade por parte do empreendedor, da mesma, que se apresenta como resultado do planejamento urbano que estabelece zonas com base em critérios econômicos.

Como resultado assiste-se ao acirramento do conflito entre pedestres e automóveis, ainda que se considerem os benefícios de tais atividades para a economia do município e até mesmo para geração de urbanidade, por meio desta efervescência (NETTO, 2012). Pois, se por um lado os atacarejos dinamizam o espaço urbano e possibilitam diferentes encontros, servem-se e até mesmo dependem da fluidez, que, por sua vez, é possibilitada por vias de trânsito rápido, viadutos, trincheiras, dentre outros equipamentos, que geram cicatrizes urbanas (Duarte, 2006) e a perda dos referenciais fragmentando o espaço da cidade. Na figura 14 é possível observar algumas áreas no interior da cidade onde estão presentes as rodovias e trincheiras.

Figuras 14 - Uberlândia-MG: Rodovias e trincheiras no perímetro urbano (2019).

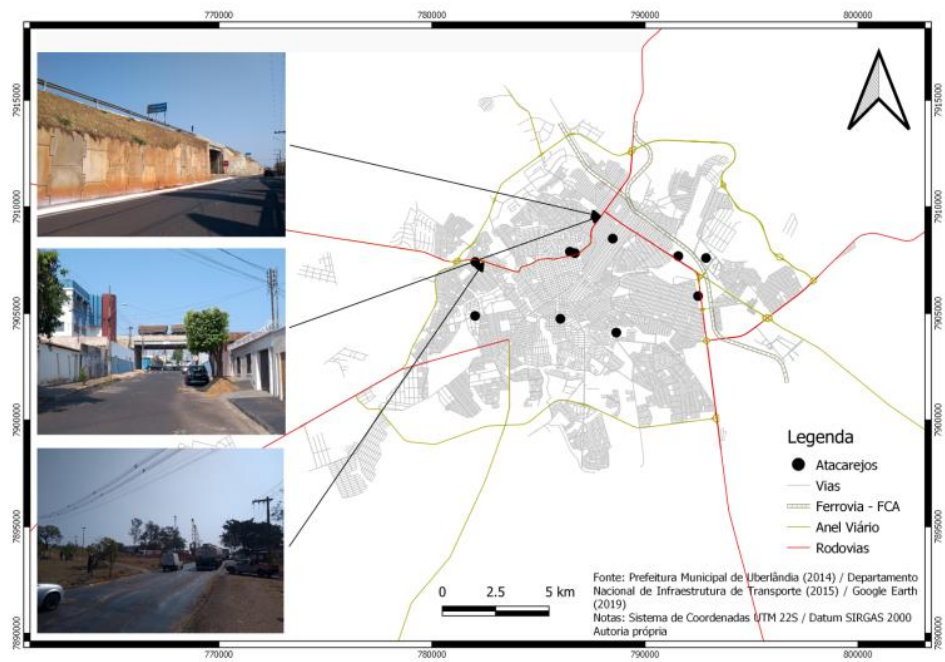

Fonte: dos autores (2019) 


\section{CONSIDERAÇÕES FINAIS}

A estruturação do espaço das cidades tem estreita relação com o comércio (VARGAS, 2001). Todavia, o comércio assume diferentes formas de acordo com as atividades realizadas em determinado local, o que gera também uma diferenciação entre os espaços - por meio da especialização funcional. Nesse contexto, observa-se que os espaços vão assumindo formas distintas de acordo com as funções ali presentes.

O comércio e distribuição de mercadorias e as operações logísticas constituem uma parcela significativa das atividades do Terciário na periferia urbana. Estas atividades demandam espaço e fluidez para 0 transporte $e$ armazenamento de mercadorias. Assim, exigem para sua realização, uma série de infraestruturas que garantam a eficiência e a eficácia do Supply Chain Management (Gerenciamento da Cadeia de Suprimento).

O município de Uberlândia-MG, que surge como entreposto comercial na Via do Anhanguera (século XIX) teve seu desenvolvimento econômico e urbano atrelado às atividades de comércio e distribuição de mercadorias. Estas atividades assumem maior importância na estruturação da cidade da década de 1950 em diante, com a abertura de grandes empresas locais especializadas no comércio e distribuição de mercadorias.

Com o desenvolvimento da atividade na cidade e devido à atuação de agentes locais, tanto na política, quanto na economia, uma série de equipamentos e infraestruturas foram instalados em Uberlândia, tais como: nova estação ferroviária, o Distrito Industrial na década de 1970 e as rodovias federais. Isto possibilitou a expansão das atividades logísticas nesse espaço e resultou na atração de empresas do setor atacadista e na diversificação das modalidades do setor presentes na cidade. Empresas de atacado de autosserviço e operação logística passaram a se instalar no interior e nas bordas da malha urbana de Uberlândia - na periferia urbana.

Ao atrair grandes fluxos em uma distribuição espacial específica, os atacadistas influenciam na forma como a cidade (no caso a periferia urbana) é configurada. Em se tratando dos atacadistas de autosserviço, dada suas estratégias de marketing e o mix de produtos que trabalham, além de sua forma de atuação, a qual se dá também na modalidade varejo, percebe-se um novo padrão de deslocamentos no interior da cidade. As áreas em que esses estabelecimentos se instalam apresentam assim, rápidas e significativas transformações, tanto em sua forma, quanto em sua dinâmica.

No caso de Uberlândia, essa distribuição trazida pelos atacadistas levou a uma nova estruturação (cindindo o tecido urbano, gerando um novo padrão espacial, ratificando o modelo rodoviarista e estabelecendo uma escala diversa ao pedestre). Ao mesmo tempo em que esses estabelecimentos dinamizam a economia e o próprio espaço da cidade, geram também rupturas, sobretudo pelo fato de intensificarem o fluxo de veículos no interior da cidade, o que acaba por aumentar a tensão entre pedestres e veículos, além de contribuir para a degradação do ambiente edificado à sua volta.

O padrão construtivo constituído por galpões assentados sobre grandes platôs terraplanados constitui-se como barreira à circulação, dificultando a mobilidade dos moradores do entorno. $O$ fato é agravado pela complementação do uso do solo com outras tipologias assemelhadas. Nesse caso, nota-se a aglomeração de outros galpões de distribuição e armazenagem de mercadorias, bem como atividades pesadas de comércio e serviços que orbitam e complementam os atacarejos.

Os resultados dessa formatação do ambiente construído - fluxos e forma construída - legam ao entorno significativo impacto, materializado na forma de trincheiras rodoviárias que configuram espaços de fluxos de alta velocidade e peso, zonas proibitivas aos pedestres. A escala e a forma edificada, por sua vez conflitam com a das pequenas residências com que fazem fronteiras criando uma atmosfera altamente degradada e a absoluta ausência de espaços públicos e subtrai a possibilidade da caminhada, como pode ser visto na figura 14. Paradoxalmente, os atacarejos estabelecem relação estreita com o entorno ao configurarem-se como lugares de trabalho e abastecimento para essas populações. No entanto, as péssimas condições de acessibilidade a partir de áreas próximas, bem como a velocidade com que os fluxos motorizados acontecem constroem uma cena comum, vista na frenética correria de pedestres e ciclistas para transpor as rodovias para fazer compras ou trabalhar. Nesse cenário, atropelamentos e acidentes são comuns. 
O cenário encontrado pela pesquisa aponta para a necessidade de se pensar e planejar a inserção dos atacadistas de autosserviço considerando todos esses impactos na forma e na dinâmica urbana. Pois, a importância já destacada desses e de outros estabelecimentos que fomentam e dinamizam a economia do município não pode estar desvinculada de um planejamento urbano que leve em consideração a qualidade de vida dos citadinos, por meio da criação de espaços que favoreçam o encontro e a sociabilidade e que minimizem os conflitos no interior das cidades.

\section{AGRADECIMENTOS}

Agradecemos à Coordenação de Aperfeiçoamento de Pessoal de Nível Superior (Capes) pelo apoio dado a esta pesquisa, por meio da bolsa de mestrado concedida durante o período de realização da mesma.

\section{REFERÊNCIAS}

BESSA, Kelly. A dinâmica da rede urbana no Triângulo Mineiro: convergências e divergências entre Uberaba e Uberlândia. Uberlândia: Gráfica Composer Editora, 2007.

CASTELLS, Manuel. O Espaço dos Fluxos. In: A sociedade em Rede. São Paulo: Paz e Terra, 8 ed. 1992.

CÂMARA, G.; MONTEIRO, A. M. V.; MEDEIROS, J. S. FUNDAMENTOS EPISTEMOLÓGICOS DA CIÊNCIA DA GEOINFORMAČ̃̃. In: CÂMARA, G.; DAVIS, C.; A. M. V.; MEDEIROS. Introdução à Ciência da Geoinformação. Disponível em: <http://www.dpi.inpe.br/gilberto/livro/introd/cap5epistemologia.pdf>. Acesso em: janeiro de 2016.

CLEPS, G. D. G.; CARVALHO, P. F. O comércio e a produção do espaço urbano na cidade de Uberlândia-MG. In: GERARDI, Lucia Helena de Oliveira CARVALHO, Pompeu Figueiredo de. (Org.) Geografia: ações e reflexões. Rio Claro: UNESP/IGCE : AGETEO, 2006. 434 p.

CORONADO, Osmar. Logística Integrada: modelo de gestão. São Paulo: Atlas, 2007.

Instituto Brasileiro de Geografia e Estatística - IBGE. Produto Interno Bruto - Por Unidade Territorial (2010 - 2013). Rio de Janeiro: IBGE. Disponível em: <www.ibge.gov.br>. Acesso em: julho de 2015.

Instituto Brasileiro de Geografia e Estatística - IBGE. Comissão Nacional de Classificação. Disponível em: <https://concla.ibge.gov.br/busca-onlinecnae.. tml ? view $=$ secao \&tipo $=$ cnae \&versaosubclasse $=10 \&$ versaoclasse $=7 \&$ secao $=G>$. Acesso em: dezembro de 2019.

DUARTE, C. F. Forma e Movimento. Rio de Janeiro: Viana \& Mosley : Ed. PROURB, 2006. 140 p.

FERREIRA, M. C. Iniciação à análise geoespacial: teoria, técnicas e exemplos para geoprocessamento. São Paulo: Editora Unesp, 2014.

FUNDAÇÃO JOÃO PINHEIRO. Produto Interno Bruto dos municípios | 2010-2013 nova série metodologia SNA/2008. Disponível em: <www.fjp.mg.gov.br/index.php/docman/cei/pib/pibmunicipais/593-informativo-pib-dos-municipios-2010-2013/file>. Acesso em: junho de 2016.

GEHL, Jan. Cidades Para Pessoas. São Paulo: Perspectiva, 2013.

GODOI, C. N. Os circuitos de produção e os circulos de cooperação em Uberlândia-MG, Brasil. Brazilian Geographical Journal: Geosciences and Humanities research medium, Uberlândia, v. 1, n. 2, p. 243-287, jul./dec. 2010.

HARVEY, David. A produção capitalista do espaço. São Paulo: Annablume, 2005.

HILLIER, Bill. Citie as movement economies. In: Space is the machine: A configurational theory of architecture. Londres: Cambridge University Press, 2007.

LONGLEY, P. A.; GOODCHILD, M. F.; MAGUIRE, D. J.; RHIND, D. W. Sistemas e ciência da informação geográfica. Porto Alegre: Bookman, 3 ed., 2013. $540 \mathrm{p}$.

Caminhos de Geografia $\quad$ Uberlândia-MG $\quad$ v. 21, n. $75 \quad$ Jun/2020 $\quad$ p. 264-283 Página 281


MACHADO, Diogo. União Atacado encerra atividades em Uberlândia e fecha filiais. Correio de Uberlândia. 2016. Disponível em: < http://www.correiodeuberlandia.com.br/cidade-e-regiao/uniaoatacado-encerra-atividades-em-uberlandia-e-fecha-filiais/>. Acesso em: junho de 2016.

MESQUITA, Adailson Pinheiro. Dos fragmentos à totalidade?: mobilidade e legibilidade urbana de Uberlândia-MG. 2008. 373 f. Tese (Doutorado em Geografia). Universidade Federal de Uberlândia, Uberlândia, 2008.

MONTEIRO, Carolina. Trecho Urbano da BR-050 passa por recapeamento em Uberlândia. Correio de Uberlândia. 2014. Disponível em: <http://www.correiodeuberlandia.com.br/cidade-e-regiao/trechourbano-da-br-050-passa-por-recapeamento/>. Acesso em: julho de 2014.

MOURA, G. G.; SOARES, B. R. A PERIFERIA DE UBERLÂNDIA/MG: da sua origem até a sua expansão nos anos 1990. Caminhos de Geografia. Uberlândia, v. 10, n. 32, p. 22-40, 2009.

NETTO, Vinicius M. A urbanidade como devir do urbano In: AGUIAR, D.; NETTO, V. N. (Org.). Urbanidades. Rio de Janeiro: Folio Digital: Letra e Imagem, 2012, p. 33-59

OLIVEIRA, Tânia M. V. Amostragem não Probabilística: Adequação de Situações para uso e Limitações de amostras por Conveniência, Julgamento e Quotas. In: Administração On Line. São Paulo, v. 2, n. 3, 2001.

ORTIGOZA, S. A. G. Paisagens do consumo: São Paulo, Lisboa, Dubai e Seul. São Paulo: Cultura Acadêmica, 2010. https://doi.org/10.7476/9788579831287

SANTOS, Milton. A Natureza do Espaço: Técnica e Tempo, Razão e Emoção. São Paulo: Editorada Universidade de São Paulo, 4 ed., 2006. 157 p.

SOARES, Beatriz Ribeiro. Habitação e Produção do Espaço Urbano em Uberlândia. 1988. 236 f. Dissertação (Mestrado em Geografia) - Universidade de São Paulo, São Paulo, 1988.

Uberlândia: da cidade jardim ao portal do cerrado - imagens e representações no Triângulo Mineiro. 1995. 347 f.. Tese (Doutorado em Geografia) - Universidade de São Paulo, São Paulo, 1995

et al.. Uberlândia (MG): Leituras Geográficas de uma cidade média em transição. In: ELIAS, D.; SPOSITO, M. E. B.; SOARES, B. R. (Org.) Tandil e Uberlândia: agentes econômicos e reestruturação urbana e regional. São Paulo: Expressão Popular, 2010, p. 157-192

SPOSITO, M. Encarnação Beltrão. Novos conteúdos nas periferias urbanas das cidades médias do Estado de São Paulo, Brasil. Investigaciones Geográficas. México, v.54, 2004, p. 114-139.

SPOSITO, Maria Encarnação Beltrão. O desafio metodológico da abordagem interescalar no estudo de cidades médias no mundo contemporâneo. Cidades. v. 3, n.5, 2006, p. 143-157.

SPOSITO, Maria Encarnação Beltrão; SPOSITO, Eliseu Savério. Reestruturação Econômica, Reestruturação Urbana e Cidades Médias. XII Seminário Internacional RII. Belo Horizonte, 2012.

UBERLÂNDIA. Secretaria Municipal de Planejamento Urbano. Banco de Dados Integrados de Uberlândia. Disponível em: <http://uberlandia.mg.gov.br>. Acesso em: janeiro de 2014.

UBERLÂNDIA. Secretaria Municipal de Planejamento Urbano. Bairros Integrados. Disponível em: $<$ http://uberlandia.mg.gov.br>. Acesso em: julho de 2013.

UBERLÂNDIA. Lei complementar no 525, de 14 de maio de 2011. Dispõe sobre o zoneamento e ocupação do solo do Município de Uberlândia e revoga a Lei complementar $n^{\circ}$ 245, de 30 de novembro de 2000. Uberlândia, 2011

UBERLÂNDIA. Lei complementar no 535, de 21 de outubro de 2011. Adota a Classificação Nacional de Atividades Econômicas - CNAE no zoneamento do uso e ocupação do solo do Município de Uberlândia, promove alterações nos anexos III, V e VI da Lei complementar no 525 , de 14 de abril de 2011 e dá outras providências.

UBERLÂNDIA. Projeto de expansão do aeroporto de Uberlândia é apresentado. Disponível em: <http://www.uberlandia.mg.gov.br>. Acesso em: julho de 2013.

VARGAS, Heliana Comin. Espaço Terciário: o lugar, arquitetura e a imagem do comércio. São Paulo: Ed. SENAC, 2001.

$\begin{array}{llllll}\text { Caminhos de Geografia } \quad \text { Uberlândia-MG } & \text { v. 21, n. } 75 & \text { Jun/2020 } & \text { p. 264-283 Página } 282\end{array}$


VILLAÇA, Flávio. Espaço intra-urbano no Brasil. São Paulo: Studio Nobel: FAPESP: Lincoln Institute, 2001.

YAMAMOTO, Jorge Kazuo; LANDIM, Paulo M. Barbosa. Geoestatística: conceitos e aplicações. São Paulo: Oficina de Textos, 2013.

Recebido em: 04/03/2020

Aceito para publicação em: 12/05/2020 